\title{
Commentary \\ Copeptin: a new and promising diagnostic and prognostic marker
}

\author{
Mira Katan, Beat Müller and Mirjam Christ-Crain
}

Department of Endocrinology, University Hospital Basel, Petersgraben 4, CH-4031 Basel, Switzerland

Corresponding author: Mirjam Christ-Crain, mirjam.christ-crain@unibas.ch

Published: 6 March 2008

Critical Care 2008, 12:117 (doi:10.1186/cc6799)

This article is online at http://ccforum.com/content/12/2/117

(c) 2008 BioMed Central Ltd

See related research by Seligman et al., http://ccforum.com/content/12/1/R11

\begin{abstract}
The study conducted by Seligman and coworkers included in the previous issue of Critical Care demonstrates that copeptin is a promising marker to predict outcome in patients with ventilatorassociated pneumonia. In recent years, copeptin has emerged as a new prognostic marker in a variety of diseases, such as sepsis, community-acquired pneumonia, chronic obstructive pulmonary failure, heart failure and myocardial infarction. What is the pathophysiological basis for these findings? Copeptin together with vasopressin is co- secreted from the posterior pituitary and therefore mirrors the amount of vasopressin in the circulation. Vasopressin is a main secretagogue of the hypothalamo-pituitaryadrenal axis, thereby mirroring the individual stress level. Furthermore, vasopressin is an important hormone in salt and volume regulation. In this context, copeptin is also a diagnostic marker in patients with diabetes insipidus and in patients with disordered water states.
\end{abstract}

In the previous issue of Critical Care, Seligman and coworkers showed that copeptin, the C-terminal part of the vasopressin prohormone, increased continuously with the severity of sepsis [1]. Copeptin remained the only accurate prognostic marker for mortality in patients with ventilatorassociated pneumonia. Procalcitonin and the $\mathrm{PaO}_{2} / \mathrm{FiO}_{2}$ ratio, shown to be prognostic in ventilator-associated pneumonia [2], unfortunately were not included in the analysis. Nevertheless, the authors conclude that copeptin could be useful in risk-stratifying patients with ventilatorassociated pneumonia and may provide an early indication of treatment failure.

The severity of a disease influences the consumption of costly healthcare resources, including the need for intensive care admission and the suitability for discharge, among others. An early and adequate prognosis and risk assessment facilitates an optimized care of patients with severe infections and other compromising diseases. In this context, there is a potential need for readily measurable biomarkers to predict disease severity and, finally, outcome. The advantage of biomarkers is that they are rapidly and easily available and are not investigator dependent.

Copeptin is cosynthesized with vasopressin, also known as antidiuretic hormone, thereby directly mirroring vasopressin levels - but copeptin is more stable in plasma and serum [3]. Vasopressin not only has hemodynamic and osmoregulatory effects but also reflects the individual stress level. Copeptin shows identical changes during disordered water states as previously shown for vasopressin [4], and directly correlates with plasma vasopressin levels in healthy volunteers and critically ill patients.

In the past 2 years copeptin has been studied as a diagnostic marker and as a prognostic marker in different diseases. As a diagnostic marker, copeptin was evaluated in patients with diabetes insipidus - for example, after pituitary surgery. In these patients copeptin had a superior diagnostic accuracy to detect an insufficient activity of the posterior pituitary, offering an alternative to the laborious and ambiguous waterdeprivation test [5]. As a prognostic marker, copeptin levels were independent predictors of survival in critically ill patients suffering from hemorrhagic and septic shock [6]. In lower respiratory tract infections, the copeptin levels were significantly higher as compared with control individuals, with the highest levels in patients with community-acquired pneumonia [7]. Copeptin levels increased with increasing severity of pneumonia, as classified by the pneumonia severity index. Similarly, in patients with acute exacerbations of chronic obstructive pulmonary disease, copeptin was shown to be predictive of long-term clinical failure independent of age, comorbidity, hypoxemia and lung functional impairment in multivariate analysis [8].

Copeptin levels also have prognostic implications in diseases other than infections. In patients with destabilized heart failure, copeptin was an accurate prognostic marker for 
mortality $[9,10]$. In postacute myocardial infarction cases, copeptin was elevated in patients who died compared with survivors. Copeptin was thereby a significant independent predictor of death or heart failure within 60 days [11].

Why is copeptin a good prognostic tool in a variety of diseases? Vasopressin, together with corticotropin-releasing hormone, is the main secretagogue of the hypothalamopituitary-adrenal axis to produce adrenocorticotropic hormone and cortisol. Serum cortisol levels have been reported to be proportionate to the degree of stress and, by mirroring the individual stress level, to predict outcome in sepsis and pneumonia [12]. Importantly, copeptin levels seem to mirror even more subtly moderate levels of stress than cortisol levels [13].

Copeptin analysis may be suitable to answer vital clinical questions. For the critical care clinician, this analysis could be particularly helpful in patients where knowledge of endogenous vasopressin, mirrored by copeptin concentrations, is crucial for therapy [14], such as in patients with prolonged hypotension and ongoing vasopressor drug requirements [15] or in patients with electrolyte disturbances.

Of course, any biomarkers will always oversimplify the interpretation of important variables, and therefore biomarkers are meant to complement, rather than to supersede, the judgment of clinicians and/or validated clinical severity scores. Conceptually, the likelihood of an adverse outcome should determine the medical indication, the length of hospitalization and the allocation of healthcare resources. It is time to perform intervention studies using biomarkers such as copeptin in specific settings to guide the allocation of hospital resources, including the need for intensive care admission and duration to ultimately prove their clinical usefulness and cost-efficiency.

\section{Competing interests}

The authors declare that they have no competing interests.

\section{References}

1. Seligman R, Papassotiriou J, Morgenthaler NG, Meisner M, Teixeira PJ: Copeptin, a novel prognostic biomarker in ventilatorassociated pneumonia. Crit Care 2008, 12:R11.

2. Luyt CE, Guerin V, Combes A, Trouillet JL, Ayed SB, Bernard M, Gibert C, Chastre J: Procalcitonin kinetics as a prognostic marker of ventilator-associated pneumonia. Am J Respir Crit Care Med 2005, 171:48-53.

3. Morgenthaler NG, Struck J, Alonso C, Bergmann A: Assay for the measurement of copeptin, a stable peptide derived from the precursor of vasopressin. Clin Chem 2006, 52:112-119.

4. Szinnai G, Morgenthaler NG, Berneis K, Struck J, Muller B, Keller $\mathrm{U}$, Christ-Crain M: Changes in plasma copeptin, the c-terminal portion of arginine vasopressin during water deprivation and excess in healthy subjects. J Clin Endocrinol Metab 2007, 92: 3973-3978.

5. Katan M, Morgenthaler N, Dixit K, Rutishauser J, Brabant G, Muller $B$, Christ-Crain $M$ : Anterior and posterior pituitary function testing with simultaneous insulin tolerance test and a novel copeptin assay. J Clin Endocrinol Metab 2007, 92:2640-2643.

6. Morgenthaler NG, Muller B, Struck J, Bergmann A, Redl H, Christ-
Crain M: Copeptin, a stable peptide of the arginine vasopressin precursor, is elevated in hemorrhagic and septic shock. Shock 2007, 28:219-226.

7. Muller B, Morgenthaler N, Stolz D, Schuetz P, Muller C, Bingisser R, Bergmann A, Tamm M, Christ-Crain M: Circulating levels of copeptin, a novel biomarker, in lower respiratory tract infections. Eur J Clin Invest 2007, 37:145-152.

8. Stolz D, Christ-Crain M, Morgenthaler NG, Leuppi J, Miedinger D, Bingisser R, Muller C, Struck J, Muller B, Tamm M: Copeptin, Creactive protein, and procalcitonin as prognostic biomarkers in acute exacerbation of COPD. Chest 2007, 131:1058-1067.

9. Gegenhuber A, Struck J, Dieplinger B, Poelz W, Pacher R, Morgenthaler NG, Bergmann A, Haltmayer M, Mueller T: Comparative evaluation of $B$-type natriuretic peptide, mid-regional pro-A-type natriuretic peptide, mid-regional pro-adrenomedullin, and copeptin to predict 1-year mortality in patients with acute destabilized heart failure. J Card Fail 2007, 13:4249.

10. Stoiser B, Mortl D, Hulsmann M, Berger R, Struck J, Morgenthaler NG, Bergmann A, Pacher R: Copeptin, a fragment of the vasopressin precursor, as a novel predictor of outcome in heart failure. Eur J Clin Invest 2006, 36:771-778.

11. Khan SQ, Dhillon OS, O'Brien RJ, Struck J, Quinn PA, Morgenthaler NG, Squire IB, Davies JE, Bergmann A, Ng LL: C-terminal provasopressin (copeptin) as a novel and prognostic marker in acute myocardial infarction: Leicester Acute Myocardial Infarction Peptide (LAMP) study. Circulation 2007, 115:21032110.

12. Christ-Crain $M$, Stolz D, Jutla $S$, Couppis $O$, Muller $C$, Bingisser $R$, Schuetz P, Tamm M, Edwards R, Muller B, Grossman AB: Free and total cortisol levels as predictors of severity and outcome in community-acquired pneumonia. Am J Respir Crit Care Med 2007, 176:913-920.

13. Katan M, Morgenthaler NG, Widmer I, Puder J, König C, M MBaC$\mathrm{C}$ : Copeptin, a stable peptide derived from the vasopressin precursor, correlates with the individual stress level. Neuro Endocrinol Lett 2008, 29:in press.

14. Robertson GL: The use of vasopressin assays in physiology and pathophysiology. Semin Nephrol 1994, 14:368-383.

15. Morales DL, Garrido MJ, Madigan JD, Helman DN, Faber J, Williams MR, Landry DW, Oz MC: A double-blind randomized trial: prophylactic vasopressin reduces hypotension after cardiopulmonary bypass. Ann Thorac Surg 2003, 75:926-930. 